\title{
Fluorescent dissolved organic matter is a tool to assess fluid source and mixing in terrestrial hot springs
}

\author{
HILAIRY E. HARTNETT ${ }^{1,2}$ AND JOSHUA J. NYE ${ }^{1}$
}

${ }^{1}$ School of Earth and Space Exploration, Arizona State

Unviersity, Tempe AZ 85287. h. hartnett@asu.edu

${ }^{2}$ School of Molecular Sciences, Arizona State University,

Tempe AZ 85287

Dissolved organic matter (DOM) in hot spring systems is a complex, dynamic pool of molecules with multiple sources and fates. Recently, we developed a novel PARAFAC model for hot spring DOM that revealed a unique fluorphore in acidic springs $(\mathrm{pH}<4$; [1]). Here we assess DOC concentration and DOM fluorescence characteristics for $\sim 200$ hydrothermal features in Yellowstone National Park that span a range of hot spring types. A plot of [DOC] as a function of sulfate, chloride, and $\mathrm{pH}$ (Fig. 1) confirms typical mixing patterns identified using sulfate and chloride alone [2]. However, fluorescent DOM is a sensitive tracer of surface derived organic matter and allows us to distinguish mixing between different source types even when they have similar sulfate-chloride. It also allows us to assess the extent to which mixing has occurred subsurface without terrestrial influence vs. at the surface manifestation of the spring.

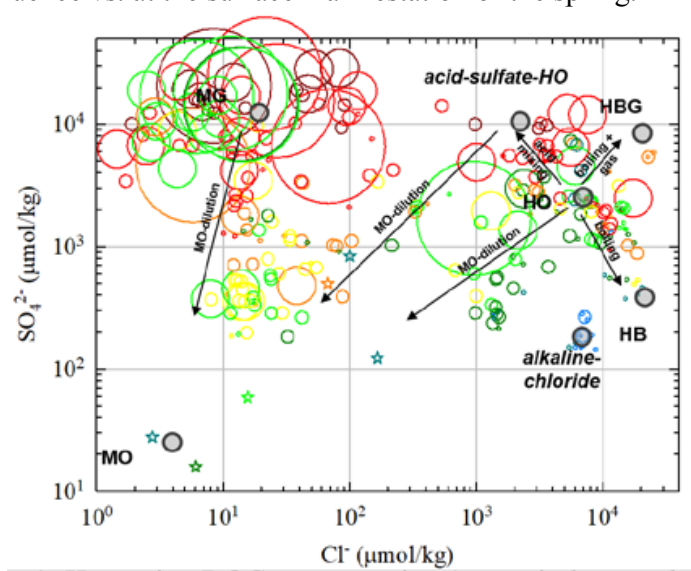

Fig. 1: Hot spring DOC concentration (open circles, symbol size $\propto$ concentration; range: $15-3000 \mu \mathrm{M}$ ) plotted in molal $\left[\mathrm{SO}_{4}{ }\right]$ vs. $[\mathrm{Cl}]$ space. Color scale is $\mathrm{pH}$ (red-orange: $\mathrm{pH}<4$; yellow-green: $4<\mathrm{pH}<7$; blue: $\mathrm{pH}>7$ ). Mixing trends and fluid types from [2] are overlain as arrows and shaded circles.

[1] J Nye, E Shock, H Hartnett (2020 in press) Org. Geochem. doi.org/10.1016/j.orggeochem.2019.103964

[2] D Nordstrom, R McCleskey, J Ball (2009) Appl. Geochem. 24(1): 191-207 